\title{
Effect of Equal Channel Angular Pressing (ECAP) on Microstructure and Properties of Al-FeAlCr Intermetallic Phase Composites
}

\author{
Kátia Regina Cardoso ${ }^{\text {a*, Maria A. Muñoz-Morris }}{ }^{\mathrm{b}}$,Marcela Lieblich ${ }^{\mathrm{b}}$, David Morris ${ }^{\mathrm{b}}$ \\ ${ }^{a}$ Instituto de Ciência e Tecnologia - ICT, Universidade Federal de São Paulo-UNIFESP, \\ Rua Talim, 330, CEP 12231-280, São José dos Campos, SP, Brazil \\ ${ }^{\mathrm{b}}$ Department of Physical Metallurgy, CENIM, CSIC, Avenida Gregorio del Amo 8, 28040 Madrid, Spain
}

Received: December 3, 2013; Revised: February 14, 2014

\begin{abstract}
An aluminium matrix composite was prepared by mixing commercial aluminium powders and $15 \mathrm{vol} \%$ of FeAlCr powders and consolidation by hot extrusion. The extruded composite was subjected to severe plastic deformation by equal channel angular pressing (ECAP) at room temperature and at $150^{\circ} \mathrm{C}$. The extruded composite presents a uniform distribution of particles although some defects are observed such as residual pores and particle agglomerates. The particle distribution does not show a significant change due to ECAP. The extruded composite exhibits a relatively fine grain size of the order of 1-2 $\mu \mathrm{m}$ that was refined to $550 \mathrm{~nm}$ after three ECAP passes at room temperature by route A and to $636 \mathrm{~nm}$ after four passes at $150^{\circ} \mathrm{C}$ by route $\mathrm{Bc}$. The yield stress of the composites was increased by 140 to $180 \%$ after ECAP as compared with the extruded condition.
\end{abstract}

Keywords: ECAP, composite, aluminium, intermetallic

\section{Introduction}

Particle reinforced aluminium matrix composites are of great interest as structural materials due to their high stiffness and specific strength beyond isotropic properties, in general superior to those of conventional aluminium alloys ${ }^{1}$. Aluminium matrix composites reinforced with intermetallic particles present some advantages over those reinforced with ceramic particles ${ }^{2}$. Intermetallic phases present thermal expansion coefficients closer to those of the aluminium matrix, causing smaller residual stresses at the interface and reducing thermal fatigue ${ }^{3}$. The intermetallic phases are also less abrasive to the antagonist surface in wear conditions resulting in longer life of tools used in their machining ${ }^{4}$.

However, there are some limitations that require a greater amount of research and development, as the high reactivity of intermetallic phases with aluminium and the greater density of intermetallic compared with some ceramics, a problem that could be overcome by using nanoscale particles which would reduce the volume fraction without loss of properties ${ }^{5,6}$. The great challenge is to increase the mechanical strength of intermetallic reinforced aluminium at room temperature combined with good ductility, which requires good cohesion at the particle - matrix interface. In addition, maintaining the mechanical properties at relatively high temperatures is crucial in certain applications, which require the thermal stability not only of reinforcing particles but also of the matrix microstructure.

Severe plastic deformation by Equal Channel Angular Pressing (ECAP) has been extensively used as a way to refine microstructures of ductile metals and alloys and to improve mechanical behaviour ${ }^{7,8}$. Recently, SPD methods as ECAP began to be used in the aluminium matrix composite

*e-mail: krcardoso@unifesp.br reinforced by ceramic or intermetallic particles resulting in refined microstructure with grain size of about 200-300 $\mathrm{nm}$, a more homogeneous distribution of reinforcement particles and improved mechanical strength ${ }^{9-14}$. Fatigue life and strength have also been increased with use of ECAP ${ }^{13,15}$.

The iron aluminides are very attractive materials for technological applications at elevated temperatures due to its characteristics such as low density and low cost as compared with other intermetalic materials. However, these intermetallic compounds have low ductility at room temperature, which can be improved by controlling the grain size to less than $1 \mu \mathrm{m}$ and by dispersing fine and homogeneous particles of a second phase in the alloy matrix that contribute to a more homogeneous plastic deformation and cause delay in crack nucleation ${ }^{16}$. The addition of $\mathrm{Cr}$ to $\mathrm{Fe}$ aluminides tends also to minimize embrittlement of these compounds at room temperature.

In this work an aluminium matrix composite reinforced with particles of an $\mathrm{FeAlCr}$ intermetallic phase was processed by the powder metallurgy route with hot extrusion consolidation. The $\mathrm{FeAlCr}$ phase is an yttria dispersed strengthened alloy commercially produced by high energy ball milling. This study aims to evaluate the effect of processing by ECAP on microstructure and mechanical properties of this composite. The effect of different parameters during ECAP process such as temperature, processing route and number of passes is evaluated.

\section{Experimental Procedure}

The composites were prepared by mixing powders of commercially pure aluminium (99.5\%) obtained by gas atomization with $\mathrm{FeAlCr}$ intermetallic particles as the 
reinforcement phase. The FeAlCr powders were supplied by Plansee and were obtained by high energy ball milling with a composition $\mathrm{Fe}-39 \mathrm{Al}-10 \mathrm{Cr}$ (atomic percent) and an addition of $0.2 \%$ volume fraction of $\mathrm{Y}_{2} \mathrm{O}_{3}$ particles.

The aluminium powders were mixed with $15 \%$ volume intermetallic alloy powder in a planetary type mill, Pulverisette 7 , without balls and using a rotation speed of $800 \mathrm{rpm}$ for 30 minutes. The powder mixture was encapsulated in an aluminium can and extruded at $400{ }^{\circ} \mathrm{C}$ by using an extrusion ratio of 5:1 to produce bars of $20 \mathrm{~mm}$ diameter to be processed by ECAP. These bars were cut into cylinders of $20 \mathrm{~mm}$ in diameter, $70 \mathrm{~mm}$ long, for ECAP processing.

ECAP was carried out at room temperature (RT) and $150^{\circ} \mathrm{C}$, by routes $\mathrm{A}$ and $\mathrm{B}_{\mathrm{C}}$, in a hydraulic machine using a circular cross-section die of diameter $20 \mathrm{~mm}$ with die angle of $118^{\circ}$, producing a true strain of 0.7 per pass. For ECAP at $150^{\circ} \mathrm{C}$, samples were heated in a die, reaching die temperature in $5 \mathrm{~min}$ before pressing. At the standard pressing speed $(20 \mathrm{~mm} / \mathrm{min})$ the total cycle time (preheating and pressing) was $10 \mathrm{~min}$. Following each ECAP pass, the heated split-die was opened hydraulically for rapid sample removal and water quenching.

Microstructural characterization of the composite was performed by scanning electron microscopy (SEM) using a HITACHI S-4800 instrument equipped with a Cold Field Emission filament on transverse sections through the as extruded bar and ECAP cylinders. Quantitative image analysis was carried out to follow the evolution of FeAlCr particle size and matrix grain size during successive ECAP passes. Grain sizes were measured from SEM images obtained using Backscattered Electrons counting at least 300 grains in each case. FeAlCr particles were quantified by measuring about 1000 particles from SEM images in each case. Particle and grain sizes were both determined as the equivalent diameter value that is the diameter of the circle having the same area as the given particle/grain. Statistical measurements of particle and grain sizes were carried out with the softwares Image-Pro Plus and Sigma Scan Pro, respectively, and taking the median, value above and below which $50 \%$ of the sizes are found, to represent the average sizes.

The mechanical properties of the as extruded bars and ECAP processed material were evaluated by tensile or compression testing. The choice of test method between tensile or compression was based on the possibility of machining tensile specimens, once processing cracks in less ductile samples may derail the withdrawal of the specimens. The mechanical tests were performed in a universal testing machine manufactured by MICROTEST equipped with a load cell of $20 \mathrm{kN}$. For tensile testing, cylindrical samples of diameter $3 \mathrm{~mm}$ and gauge length $20 \mathrm{~mm}$ were used whilst for compression tests the samples were cylinders of $3 \mathrm{~mm}$ in diameter and height 5-6 mm. Three samples of each condition were tested at room temperature and at strain rate of $4 \times 10^{-4} \mathrm{~s}^{-1}$. All samples were tested along the direction of ECAP or extrusion processing.

\section{Results and Discussion}

Figure 1 shows examples of the microstructure of composite after extrusion. Although the particles are relatively well distributed, the microstructure exhibits areas with clusters of the reinforcement particles besides some residual pores. These defects may have been responsible for the decrease in ductility of the composite which hindered its processing by ECAP mainly at room temperature with cracks appearing on the surface after only two passes. At $150^{\circ} \mathrm{C}$ it was possible to process by ECAP up to 4 passes before the appearance of cracks.

The microstructure of the composite after ECAP is very similar to that of the extruded material concerning the size and distribution of the reinforcement particles although an apparent better cohesion at the interface matrix/ reinforcement is observed after ECAP, Figure 2. ECAP seems to affect the intermetallic particles size very little, cracks and fractures being not very significant. Further, no second phases produced by reaction at the interface matrix/ particle were observed after extrusion or ECAP.

Quantitative image analysis confirmed that there was no significant change in the distribution of particle

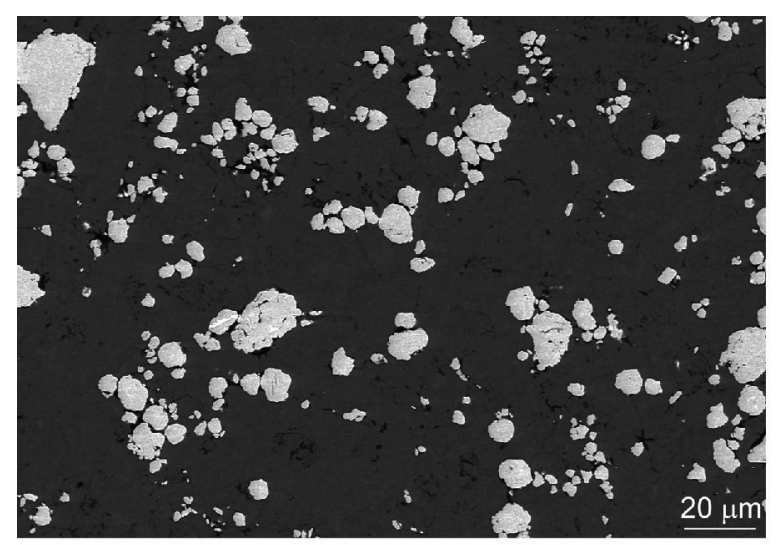

(a)

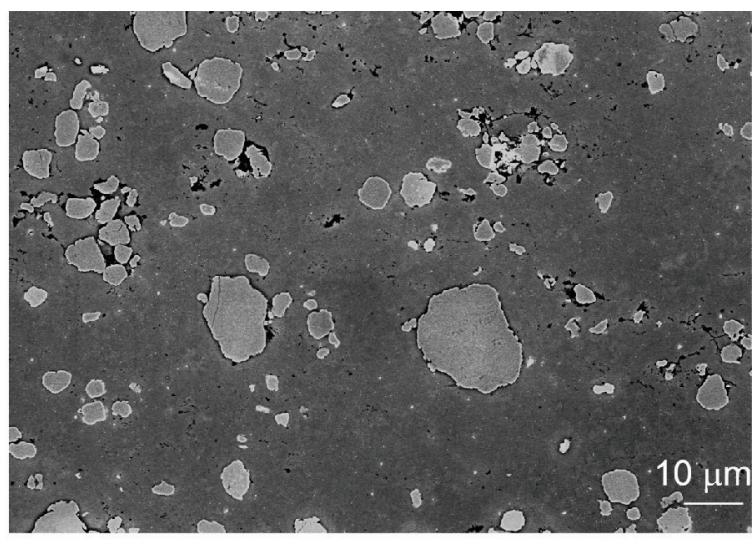

(b)

Figure 1. SEM images showing FeAlCr particles distribution in the as extruded condition. (a) image obtained by back-scattered electron contrast; (b) image obtained by secondary electrons. 
sizes between the as extruded and ECAP conditions. The particle sizes obtained from the quantitative analysis of composites are approximately $3 \mu \mathrm{m}$, assuming the median of the distribution, or $4 \mu \mathrm{m}$ if mean value is assumed. Figure 3 shows examples of histograms of particle sizes (Feret diameter) measured in the as-extruded condition and after three ECAP passes at room temperature, in which the dispersion particle size for each sample condition can be inferred. The standard deviation for these two samples was 3.6 and 3.8, respectively.

Micrographs showing the evolution of grain size with number of ECAP passes for the two different routes together with an example of as extruded condition are shown in Figure 4. The grain size measured for each sample was considered as the median of their respective size distributions. The grain size measurements are shown in Table 1 together with the values of reinforcement particle size. The dispersion in measures of grain size was plus or minus $25 \mathrm{~nm}$ for all cases being described as the range of classes used. It is worth noting that the crystallographic contrast technique used to obtain the images does not distinguish between low, medium or high angle boundaries so that no distinction is made in the measurements of the grain size. The initial grain size measured in the conventionally extruded material was $2.0 \mu \mathrm{m}$.

The decrease in grain size from this large initial value seems to depend on the ECAP route. At room temperature, route A produces a rapid initial grain size reduction, to $593 \mathrm{~nm}$ after only two ECAP passes, with a near-saturation thereafter, to $557 \mathrm{~nm}$ after three passes. In contrast, route $\mathrm{B}_{\mathrm{C}}$ seems to produce a slower grain refinement, reaching $576 \mathrm{~nm}$ after four passes. At $150^{\circ} \mathrm{C}$ the grain size measurements show an opposite behaviour to that obtained at room temperature. After four ECAP passes a smaller grain size was obtained by route $B_{C}$. These results can be explained by the differences in dislocation accumulation in the aluminium matrix with the routes ${ }^{17,18}$. By route $\mathrm{A}$ there is a faster dislocation accumulation at the low-angle boundaries which subdivide the original grains into smaller ones producing boundaries of higher misorientation and smaller grain size. On the other hand when route $B_{C}$ is used, the partial annihilation of dislocations that occurs with

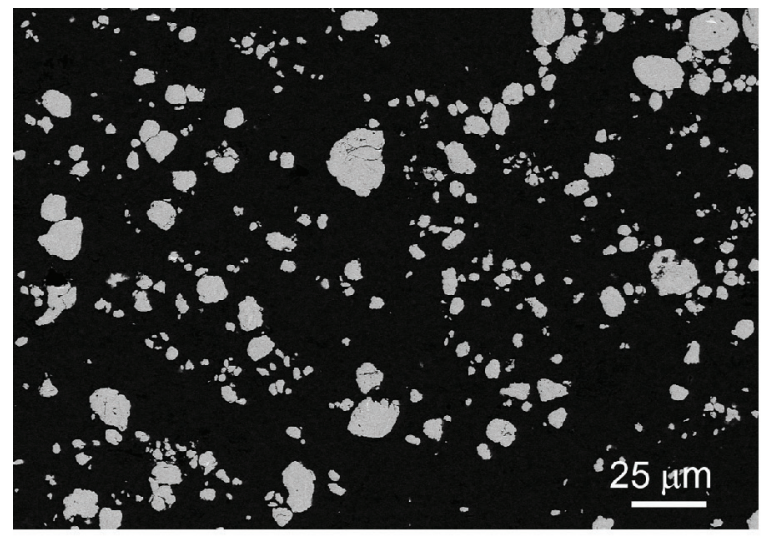

(a)

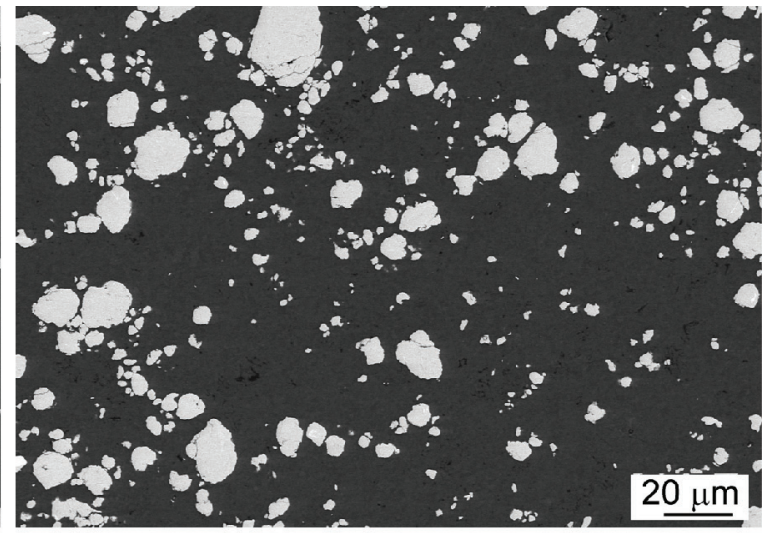

(b)

Figure 2. SEM images obtained by back-scattered electrons showing FeAlCr particles distribution in composite after ECAP. (a) 3 ECAP passes at RT by route $\mathrm{A}$; (b) 4 ECAP passes at $150^{\circ} \mathrm{C}$ by route $\mathrm{B}_{\mathrm{C}}$

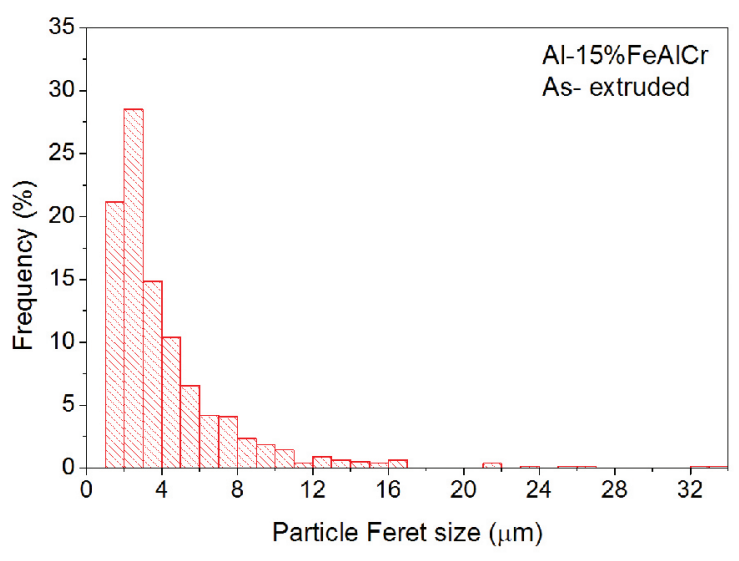

(a)

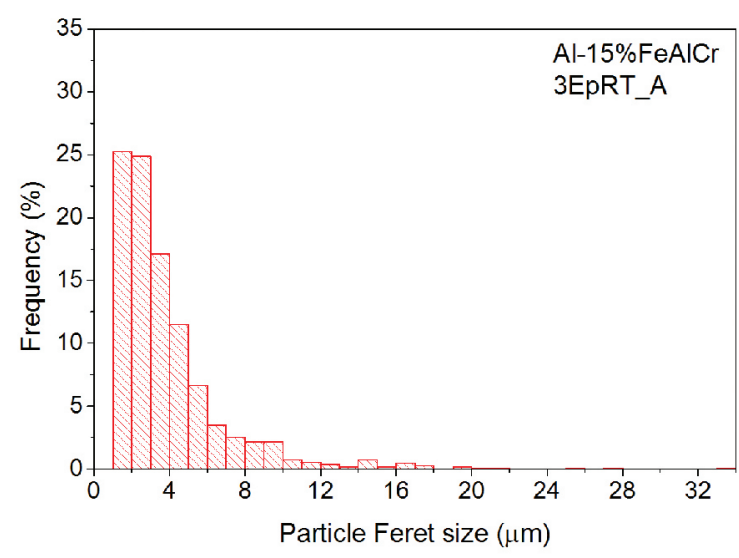

(b)

Figure 3. Histograms showing FeAlCr particle size distribution in as-extruded and after 3 ECAP passes at room temperature by route A. 


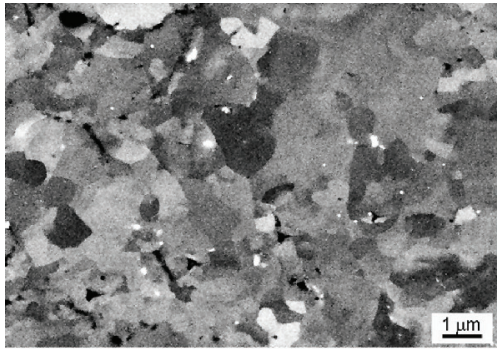

(a)

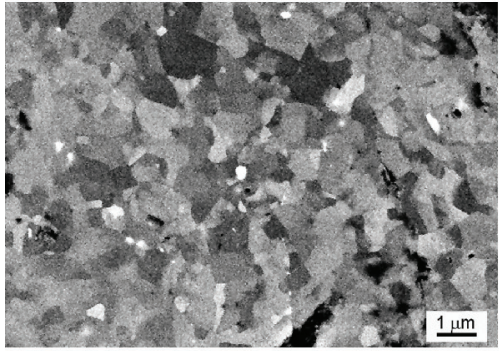

(d)

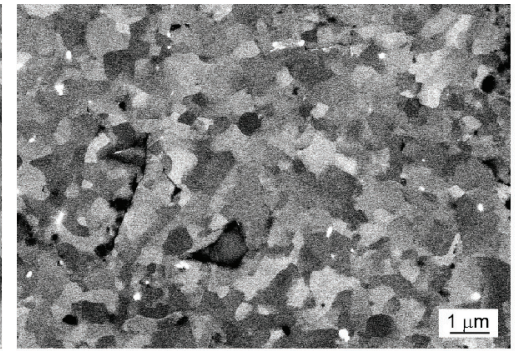

(b)

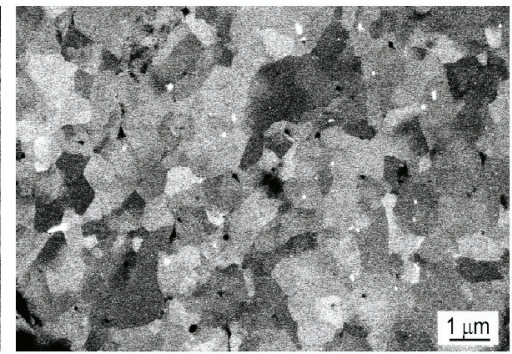

(e)

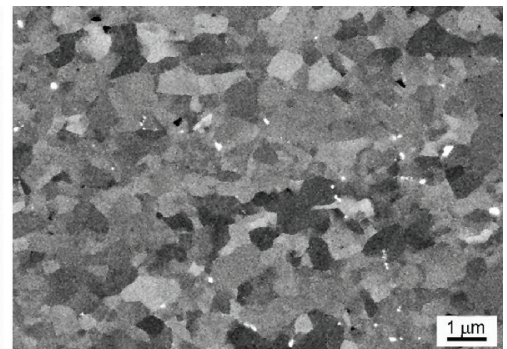

(c)

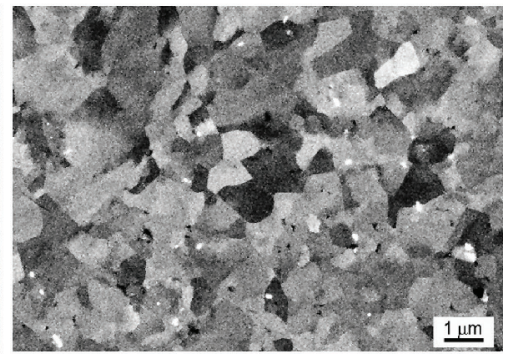

(f)

Figure 4. SEM images obtained by crystallographic contrast using back-scattered electron, showing grain sizes in the aluminium matrix of the composite. (a) extruded condition; (b) 2 ECAP passes by route A at room temperature; (c) 3 ECAP passes by route A at room temperature; (d) 4 ECAP passes by route $\mathrm{B}_{\mathrm{C}}$ at room temperature; (e) 4 ECAP passes by route $\mathrm{A}$ at $150^{\circ} \mathrm{C}$; (f) 4 ECAP passes by route $\mathrm{B}_{\mathrm{C}}$ at $150^{\circ} \mathrm{C}$.

Table 1. FeAlCr particle size, grain size, experimental yield stress $\left(\sigma_{\mathrm{y}}\right)$, tensile stress $\left(\sigma_{\max }\right)$ and tensile ductility for the composite in the as extruded condition and after ECAP.

\begin{tabular}{lccccc}
\hline $\begin{array}{c}\text { Material } \\
\text { Condition }\end{array}$ & $\begin{array}{c}\text { FeAICr particle } \\
\text { size }(\mu \mathbf{m})\end{array}$ & $\begin{array}{c}\text { Grain size } \\
(\mathbf{n m})\end{array}$ & $\begin{array}{c}\sigma_{\mathbf{y}} \\
(\mathbf{M P a})\end{array}$ & $\begin{array}{c}\sigma_{\max } \\
(\mathbf{M P a})\end{array}$ & $\begin{array}{c}\text { Ductility } \\
(\boldsymbol{\%})\end{array}$ \\
\hline As extruded & 3.0 & 2000 & $58^{*}$ & - & - \\
2EpRT_A & 2.9 & 593 & 164 & 169 & 2.5 \\
3EpRT_A & 3.0 & 557 & 156 & 162 & 3 \\
4EpRT_B & 3.1 & 576 & $146 *$ & 148 & - \\
4Ep150_A & 3.0 & 744 & 143 & 145 & 4 \\
4Ep150_B & 2.9 & 636 & 141 & & 3 \\
\hline
\end{tabular}

*As extruded and 4 EpRT- $\mathrm{B}_{\mathrm{C}}$ samples were tested in compression to determine flow stress.

alternate passes leads to a slower dislocation accumulation and consequently to smaller misorientation and larger grain size. The same effect can be responsible by the effect at $150^{\circ} \mathrm{C}$. At this temperature, recovery with annihilation of dislocations is thermally assisted but the driving force is higher the greater the accumulated deformation, which results in a slighter larger grain size by route A. At the same time, the slower dislocation accumulation by route $\mathrm{B}_{\mathrm{C}}$ in the aluminium matrix would lead to reduced stress concentrations at the matrix/reinforcement interface which would produce less weakening at those interfaces, allowing the composite to be processed by ECAP at room temperature by a greater number of passes through this route before the appearance of cracks $^{17,19}$.

The results obtained from tensile and compression tests of composite in the as extruded and after all conditions of ECAP processing are summarised in Table 1. The values presented are mean values obtained from three measurements with standard deviations always smaller than 5.0. The as extruded sample was brittle when tested in tension, so compression testing was used to measure the yield stress. The sample 4EpRT_B ${ }_{C}$ was also tested in compression as it had a large number of cracks after ECAP, fact that prevented machining tensile specimens. The composite in the as extruded condition before ECAP exhibits a very low yield stress of $58 \mathrm{MPa}$, which increases after room temperature ECAP, reaching values of about 140 to $160 \mathrm{MPa}$. ECAP processing at $150^{\circ} \mathrm{C}$ resulted in slightly smaller yield stresses and slightly higher ductility. The low value of the yield stress of the material in the extruded condition may be the result of a weak cohesion between particles and matrix and the presence of some flaws. The maximum yield stress achieved, independent of the route used, is between 140 to $180 \%$ higher than that of extruded material. All sample conditions present a low tensile ductility of about $3-4 \%$.

Although the data are limited, the results seem to show that the yield stress increases after the first few ECAP passes and then slightly decreases after three or four passes. This behaviour was also observed by Muñoz-Morris et al. ${ }^{17}$ on 


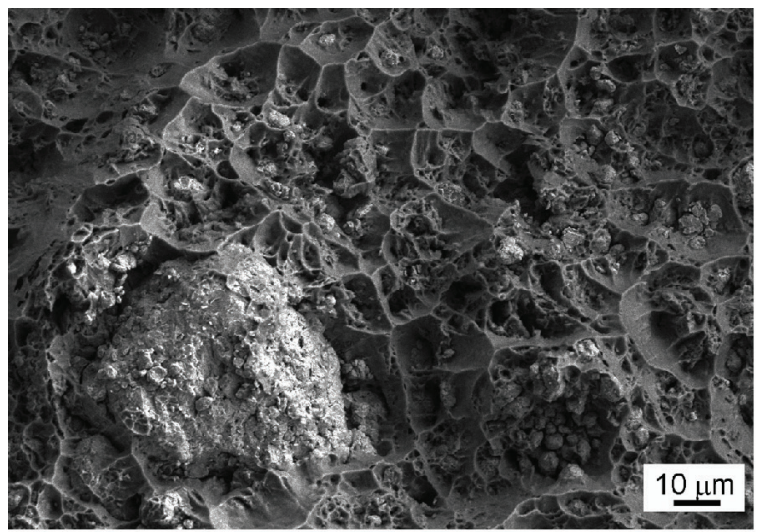

(a)

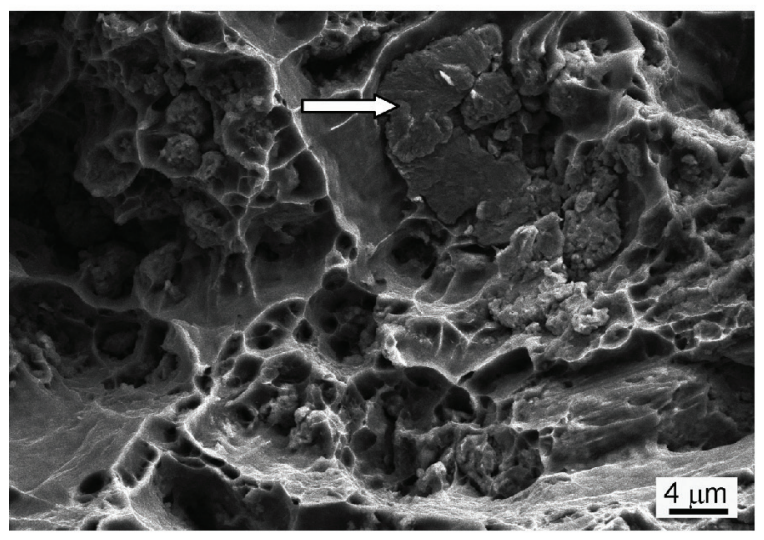

(c)

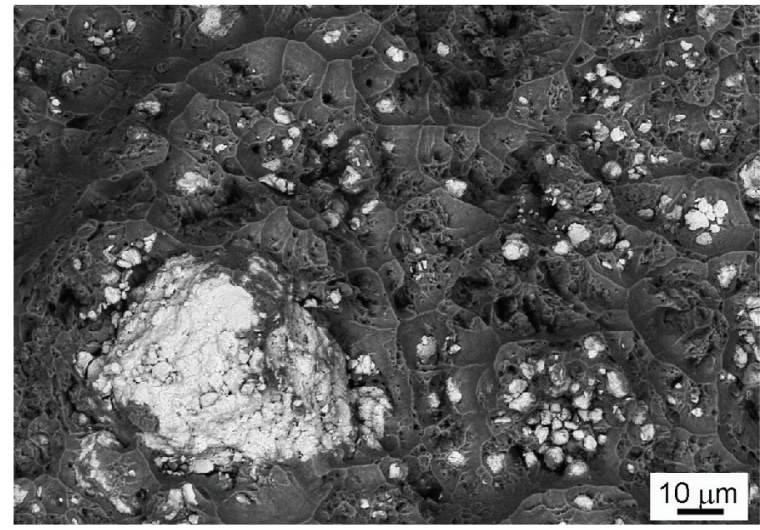

(b)

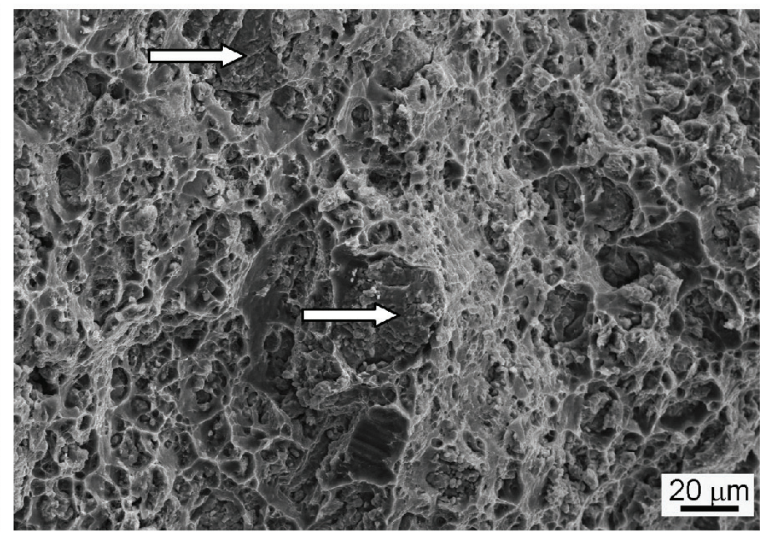

(d)

Figure 5. Fracture surface of the composite observed after tensile test at room temperature. (a), (b) and (c) 2 passes of ECAP by route A at room temperature, (d) 4 ECAP passes by route A at $150^{\circ} \mathrm{C}$. (a), (c) and (d) micrographs obtained from secondary electrons (SE) and (b) micrograph obtained with backscattered electrons (BSE) where the bright zones corresponds to fine intermetallic powders or their the agglomerates.

aluminium matrix composites reinforced with particles of TiAl, in which the yield stress increased up to four passes and after saturation showed a slight decrease with the increase in the number of passes.

The values of the yield stress of the composite processed by ECAP at room temperature are somewhat higher than those of the composite processed at $150^{\circ} \mathrm{C}$ which is quite consistent with the smaller grain size of samples that undergo ECAP at room temperature and also the presumably smaller dislocation density accumulated at $150^{\circ} \mathrm{C}$ as result of the recovery processes that take place at this temperature. Considering only the samples processed at room temperature, they exhibit grain sizes within a narrow range, from 557 to $576 \mathrm{~nm}$, so the higher yield stress values showed by the samples which undergo ECAP by route A should be related to the higher dislocation density accumulated by this route as previously discussed.

Figure 5 shows examples of the fracture surfaces observed after tensile tests, where dimples characteristic of ductile fracture of aluminium matrix can be observed. The aspect of cleavage fracture of $\mathrm{FeAlCr}$ particles can also be observed in Figures 5c and 5d as indicated by white arrows. Figures $5 \mathrm{a}$ and $5 \mathrm{~b}$ are images from the same area, using detectors for secondary and backscattered electrons respectively, and show examples of agglomerated reinforcement particles. These micrographs also bring evidence of weak cohesion between reinforcement and matrix.

\section{Conclusions}

The evolution of microstructure of extruded Al-based composites reinforced with $\mathrm{FeAlCr}$ intermetallic particles has been examined when processing by equal channel angular pressing.

Extruded composite presented a relatively homogeneous distribution of reinforcement particles in the aluminium matrix. However, some defects as pores and agglomerated particles decrease the ductility of the extruded material hindering the ECAP processing in particular at room temperature. In addition, good cohesion between the matrix and particle seems not to have been achieved.

Neither particle size nor distributions are modified by ECAP processing. ECAP reduces the matrix grain size to about $500 \mathrm{~nm}$ when performed at room temperature and about $700 \mathrm{~nm}$ when performed at $150^{\circ} \mathrm{C}$, values much below the grain size obtained after the extrusion. The larger grain sizes of the samples processed at $150^{\circ} \mathrm{C}$ was attributed to 
recovery processes with annihilation of dislocations during ECAP that led to a reduction in the rate of grain refinement.

ECAP led to a large increase in the yield stress of the composite (140 to $180 \%$ ) explained in terms of reducing the grain size of the aluminium matrix and increased dislocation density produced by the ECAP.

\section{References}

1. Corrochano J, Lieblich M and Ibáñez J. The effect of ball milling on the microstructure of powder metallurgy aluminium matrix composites reinforced with $\mathrm{MoSi}_{2}$ intermetallic particles. Composites: Part A. 2011; 42:1093-1099. http:// dx.doi.org/10.1016/j.compositesa.2011.04.014

2. Díaz C, Gonzalez-Carrasco JL, Caruana G and Lieblich M. $\mathrm{Ni}_{3} \mathrm{Al}$ intermetallic particles as wear-reinforcement for Al-base composites. Metallurgical and Materials Transactions. 1996; 27A:3259-3266. http://dx.doi.org/10.1007/ BF02663876

3. Torres B and Lieblich M. Room and high temperature tensile behavior of a P/M 2124/MoSi ${ }_{2}$ composite at different heat treatment conditions. Journal of Materials Science. 2006; 41:3493-3500. http://dx.doi.org/10.1007/ s10853-005-5678-1

4. Torres B, Campo M, Lieblich M and Rams J. Oxy-acetylene flame thermal sprayed coatings of aluminium matrix composites reinforced with $\mathrm{MoSi}_{2}$ intermetallic particles. Surface \& Coatings Technology. 2013; 236:274-283. http:// dx.doi.org/10.1016/j.surfcoat.2013.10.001

5. Omura H, Miyoshi T, Takahashi Y, Conley JG and Yodogawa M. Dispersion of $\mathrm{NiAl}$ intermetallic compound and $\mathrm{Si}_{3} \mathrm{~N}_{4}$ in die castings for increased wear resistance. In: Kim YW, Griffith WM, editors. Dispersion strengthened aluminium alloys. Warrendale: TMS; 1988. p. 421-435.

6. Gonzalez-Carrasco JL, García-Cano F, Caruana G and Lieblich M. Aluminium/Ni ${ }_{3} \mathrm{Al}$ composites processed by powder metallurgy. Materials Science and Engineering. 1994; A 183:L5-L8.

7. Valiev RZ and Langdon TG. Principles of equal-channel angular pressing as a processing tool for grain refinement. Progress in Materials Science. 2006; 51:881-981. http://dx.doi. org/10.1016/j.pmatsci.2006.02.003

8. Zhilyaev AP and Langdon TG. Using high-pressure torsion for metal processing: fundamentals and applications. Progress in Materials Science. 2008; 53:893-979. http://dx.doi. org/10.1016/j.pmatsci.2008.03.002

9. Valiev RZ, Islamgaliev RK, Kuzmina NF, Li Y and Langdon TG. Strengthening and grain refinement in an Al-6061 metal matrix composite through intense plastic straining. Scripta Materialia. 1999; 40:117-122. http://dx.doi.org/10.1016/ S1359-6462(98)00398-4

\section{Acknowledgements}

We should like to acknowledge financial support of the Spanish Ministry of Education and Science under project no.MAT2009-07342 and also the financial support of FAPESP, project no.2012/ 07536-0.

10. Mishra RS, Valiev RZ, McFadden SX, Islamgaliev RK and Mukherjee AK. Severe plastic deformation processing and high strain rate superplasticity in an aluminium matrix composite. Scripta Materialia. 1999; 40:1151-1155. http:// dx.doi.org/10.1016/S1359-6462(99)00020-2

11. Ma D, Wang $\mathrm{J}$ and $\mathrm{Xu} \mathrm{K}$. Equal channel angular pressing of a $\mathrm{SiC}$ reinforcement aluminium-based composite. Materials Letters. 2002; 56:999-1002. http://dx.doi.org/10.1016/S0167577X(02)00662-6

12. Han BQ and Langdon TG. Achieving enhanced tensile ductility in an Al-6061 composite processed by severe plastic deformation. Materials Science and Engineering A. 2005; 410411:430-434. http://dx.doi.org/10.1016/j.msea.2005.08.045

13. Sabirov I, Kolednik O, Valiev RZ and Pippan R. Equal channel angular pressing of metal matrix composites: effect on particle distribution and fracture toughness. Acta Materialia. 2005; 53:4919-4930. http://dx.doi.org/10.1016/j. actamat.2005.07.010

14. Ramu $G$ and Bauri R. Effect of equal channel angular pressing (ECAP) on microstructure and properties of Al-SiC composites. Materials and Design. 2009; 30:3554-3559. http://dx.doi. org/10.1016/j.matdes.2009.03.001

15. Chen LJ, Ma CY, Stoica GM, Liaw PK, Xu C and Langdon TG. Mechanical behavior of a $6061 \mathrm{Al}$ alloy and an Al2O3/6061 Al composite after equal-channel angular pressing. Materials Science and Engineering A. 2005; 410-411:472-475. http:// dx.doi.org/10.1016/j.msea.2005.08.117

16. Aguado MAM. Desarrollo de aleaciones $\mathrm{Fe}-\mathrm{Al}$ - $\mathrm{Cr}$ como posibles biomateriales: caracterización mecánica y comportamiento a oxidación. [Thesis]. Madrid: Facultad de Ciencias Químicas, Universidad Complutense de Madrid; 2004.

17. Muñoz-Morris MA, Calderón N, Gutierrez-Urrutia I and Morris DG. Matrix grain refinement in Al-TiAl composites by severe plastic deformation: Influence of particle size and processing route. Materials Science and Engineering A. 2006; 425:131137. http://dx.doi.org/10.1016/j.msea.2006.03.027

18. Iwahashi Y, Horita Z, Nemoto M and Langdon TG. An investigation of microstructural evolution during equal-channel angular pressing. Acta Materialia. 1997; 45:4733-4741. http:// dx.doi.org/10.1016/S1359-6454(97)00100-6

19. Muñoz-Morris MA, Gutierrez-Urrutia I and Morris G. Effect of equal channel angular pressing on strength and ductility of Al-TiAl composites. Materials Science and Engineering A. 2005; 396:3-10. http://dx.doi.org/10.1016/j. msea.2004.11.046 